\title{
Prevalence and predictors of giving birth in health facilities in Bugesera District, Rwanda
}

Shahrzad Joharifard ${ }^{1}$, Stephen Rulisa ${ }^{2,3}$, Francine Niyonkuru ${ }^{2,3}$, Andrew Weinhold ${ }^{4}$, Felix Sayinzoga 5 , Jeffrey Wilkinson ${ }^{6}$, Jan Ostermann ${ }^{7}$ and Nathan M Thielman ${ }^{7^{*}}$

\begin{abstract}
Background: The proportion of births attended by skilled health personnel is one of two indicators used to measure progress towards Millennium Development Goal 5, which aims for a 75\% reduction in global maternal mortality ratios by 2015. Rwanda has one of the highest maternal mortality ratios in the world, estimated between 249-584 maternal deaths per 100,000 live births. The objectives of this study were to quantify secular trends in health facility delivery and to identify factors that affect the uptake of intrapartum healthcare services among women living in rural villages in Bugesera District, Eastern Province, Rwanda.
\end{abstract}

Methods: Using census data and probability proportional to size cluster sampling methodology, 30 villages were selected for community-based, cross-sectional surveys of women aged 18-50 who had given birth in the previous three years. Complete obstetric histories and detailed demographic data were elicited from respondents using iPad technology. Geospatial coordinates were used to calculate the path distances between each village and its designated health center and district hospital. Bivariate and multivariate logistic regressions were used to identify factors associated with delivery in health facilities.

Results: Analysis of 3106 lifetime deliveries from 859 respondents shows a sharp increase in the percentage of health facility deliveries in recent years. Delivering a penultimate baby at a health facility $(O R=4.681[3.204-6.839])$, possessing health insurance $(O R=3.812[1.795-8.097])$, managing household finances $(O R=1.897[1.046-3.439])$, attending more antenatal care visits $(O R=1.567$ [1.163 - 2.112]), delivering more recently $(O R=1.438$ [1.120 - 1.847] annually), and living closer to a health center $(\mathrm{OR}=0.909[0.846-0.976]$ per $\mathrm{km})$ were independently associated with facility delivery.

Conclusions: The strongest correlates of facility-based delivery in Bugesera District include previous delivery at a health facility, possession of health insurance, greater financial autonomy, more recent interactions with the health system, and proximity to a health center. Recent structural interventions in Rwanda, including the rapid scale-up of community-financed health insurance, likely contributed to the dramatic improvement in the health facility delivery rate observed in our study.

Keywords: Maternal health, Service delivery, Health financing, Health systems, Sub-Saharan Africa

\footnotetext{
*Correspondence: n.thielman@dm.duke.edu

${ }^{7}$ Duke Global Health Institute, Duke University, Durham, NC, USA

Full list of author information is available at the end of the article
} 


\section{Background}

Maternal mortality remains a pressing problem in the developing world. To date, few countries are on track to meet Millennium Development Goal 5 (MDG 5), which aims for a $75 \%$ reduction in maternal mortality by 2015 $[1,2]$. The statistics are particularly alarming in subSaharan Africa, where the lifetime risk of dying from childbirth is 1 in 31, as compared to 1 in 4,300 in industrialized countries [3]. Rwanda, a densely populated country of 11 million people located in central Africa, has made impressive strides in improving its health indicators since the 1994 genocide, but still has one of the highest maternal mortality ratios in the world, estimated between 249-584 maternal deaths per 100,000 live births [1].

The proportion of births attended by skilled health personnel is one of two indicators used to track progress toward achieving MDG 5 [4]. While the debate over whether skilled attendance truly results in decreased maternal mortality remains unsettled, skilled attendance has nevertheless been adopted as a proxy indicator for maternal deaths in the developing world [5-8]. Moreover, widespread reliance on this indicator has contributed to a major shift in global policies aimed at reducing rates of maternal mortality: rather than training and equipping traditional birth attendants, efforts have increasingly been directed at improving access to and utilization of formal healthcare services during the antenatal period and at the time of delivery [5,7].

Of the eight MDG regions, sub-Saharan Africa has shown the slowest progress in increasing the proportion of births attended by skilled health personnel [6]. In Rwanda, although significant progress has been made in increasing the rates of utilization of antenatal care (ANC), improvements in the rates of utilization of delivery care have lagged. The 2007-2008 Interim Demographic and Health Survey (DHS) indicated that 95.8\% of Rwandan women attended at least one ANC visit, but that only $45.2 \%$ delivered at health facilities [9]. While the 2010 DHS shows improvement in virtually all maternal health indicators, highlighted by the $98.0 \%$ of women who reported receiving some ANC, still only $68.9 \%$ of Rwandan women reported delivering in a health facility in the five years preceding data collection [10].

Although the overall trends in these Rwanda DHS data are encouraging, the data lack granularity and provide little insight into the factors that impact women's choice of delivery location. While studies investigating this research question have been conducted in East Asia, the Indian subcontinent, and elsewhere in sub-Saharan Africa, including in neighboring Uganda, Kenya, and Tanzania [8,11-19], there is a clear need for countryspecific data given the culturally and locally specific findings of previous studies, in addition to the dramatic changes that have been made to the structure and financing of the Rwandan healthcare system in recent years [20]. The objectives of this study were to quantify secular trends in health facility delivery and to identify factors that affect the uptake of intrapartum healthcare services among women living in rural villages in Bugesera District, Eastern Province, Rwanda.

\section{Methods}

\section{Study site}

Bugesera, one of seven districts in the Eastern Province of Rwanda, comprises an area of $1337 \mathrm{~km}^{2}$ and borders Burundi on its southern edge (see Figure 1) [21]. The district is divided into 15 sectors (umurenge), which are in turn divided into 72 cells (akagari) and sub-divided into 580 villages (umudugudu). According to the most recent district census, Bugesera has a population of 299,630 people, $53.2 \%$ of which is female [22]. It is a primarily rural district with one main town, Nyamata, serving as the district capital.

All but three of Bugesera's 15 sectors have health centers, which function as primary health facilities and are staffed exclusively by nurses. In addition to the 12 health centers, there is a district hospital in Nyamata that employs 12 medical doctors. Nyamata District Hospital is the only facility in the district that offers blood transfusions, operative deliveries, and Cesarean sections. There has been the recent addition of health posts in this district, but these are primarily for the provision of outreach activities and not obstetric deliveries. If needed, patients are transported to Kigali University Teaching Hospital or King Faisal Hospital (both located in the capital, Kigali), which serve as the tertiary referral hospitals for the district.

According to the Rwandan Ministry of Health, the child mortality rate in Bugesera is 72.0 per 1,000 live births (national average $=42.0$ per 1,000 live births, rank 29 of 30 districts), while the infant mortality rate is 68.0 per 1,000 live births (national average $=60.5$ per 1,000 live births, rank 21 of 30 districts). Unfortunately, district level maternal mortality rates are not available secondary to small sample size. The Ministry's data further suggest that $66.1 \%$ of women in Bugesera deliver in health facilities (national average $=69.2 \%$, rank 16 of 30 districts), 97.4\% attend at least one ANC visit (national average $=98.0 \%$, rank 20 of 30 districts), and $21 \%$ attend at least four visits (national average $=35.4 \%$, rank 29 of 30 districts) [23]. Thus, on the whole, Bugesera has more marginal health indicators as compared to other districts in Rwanda.

\section{Study design and survey instrument}

A cross-sectional community-based study was conducted in Bugesera District during a six-week period in 


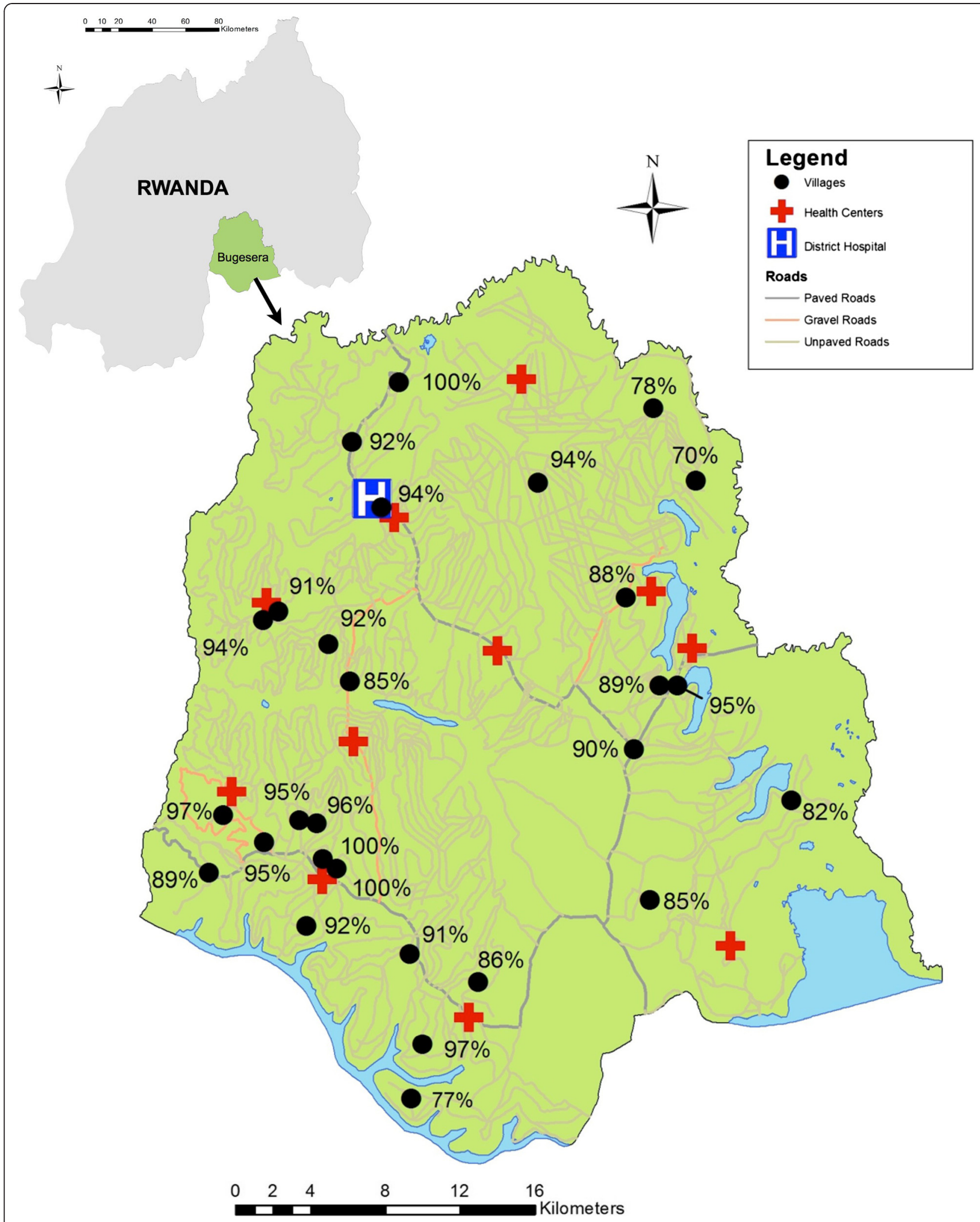

Figure 1 Map of Bugesera District with 28 sampled villages, 11 health centers, Nyamata District Hospital, and roads marked.

Percentages indicate the health facility delivery rate in each village. ${ }^{*}$ Ngeruka Health Center is not shown as the facility was not opened until September, 2010. 
March and April, 2011. A structured, quantitative survey was used to interview clusters of women aged 18-50 who had given birth in the three years preceding data collection.

The survey instrument was developed following a comprehensive literature search of quantitative and qualitative studies investigating similar research questions in low- and middle-income countries. In addition to demographic and household asset questions, respondents were asked to provide the year, delivery location, and outcome (under- 1 death, under-5 death, childhood/ adult death, offspring alive) for every pregnancy that progressed past 28 weeks. Data collectors obtained an abbreviated medical and surgical history followed by a complete obstetric history using simplified questions aimed at eliciting any history of prenatal, intrapartum, or postpartum complications. Respondents were then asked more specific questions about their last delivery, including questions regarding ANC utilization, interactions with community health workers, and details of the delivery itself.

The survey was translated into French and Kinyarwanda and back-translated into English to ensure fidelity. After ethical approval was obtained from the Kigali University Teaching Hospital Ethics Committee and the Duke University Health System Institutional Review Board, the survey instrument was converted to an electronic format using FileMaker Pro 11.0v2 (FileMaker Inc., Santa Clara, CA, USA) and uploaded to $3 \mathrm{G}$ iPads (Apple Inc., Cupertino, CA, USA) equipped with FileMaker Go 1.1 (FileMaker Inc., Santa Clara, CA, USA). An HTML script was written into the FileMaker Pro database in order to collect geospatial coordinates for each household using the iPads' $3 \mathrm{G}$ connection.

Following a week-long training period, six native Kinyarwanda speakers piloted the survey in non-sampled villages in Bugesera District to test for clarity and functionality. Based on feedback from respondents and data collectors, slight modifications were made to survey questions and FileMaker Pro programming.

\section{Sampling and sample size}

From a sampling frame of 580 villages in Bugesera District, 30 villages were randomly selected using the number of households from the 2002 census and probability proportional to size sampling methodology [24]. Data collectors were instructed to start at the main road at the edge of each village, approach the closest household, determine whether there was a woman within the household who met inclusion criteria (age 18-50 and obstetric delivery within previous three years), and obtain verbal informed consent. Data collectors systematically proceeded to the next household until they had either (a) approached every household, or (b) interviewed a total of
40 women in the village. With census data indicating a range of 26 to 306 households in sampled villages, an average household size of 4.5 , and an estimated birth rate of 41 per 1,000 women, the cutoff of 40 women per village was chosen such that all eligible women would be enrolled from most villages while ensuring that the sample would not be dominated by a few large villages.

\section{Data analysis}

Completed survey instruments were downloaded from each iPad and exported from FileMaker Pro to Microsoft Excel (Microsoft Corporation, Redmond, WA, USA) on a nightly basis. Regular data quality assurance activities were conducted and faulty survey instruments were excluded from the final database. Statistical analyses were conducted using Stata 11.2 (StataCorp, College Station, TX, USA). The mode of the household geospatial coordinates in each village was used to describe the location of each study village. Using shape files obtained from Rwanda's National Institute of Statistics, a distance analysis was run in ArcGIS 10.0 (Esri, Redlands, CA, USA) to calculate the distances traveled along roads between each village and its designated health center and Nyamata District Hospital.

Secular trends in delivery locations were described using data on all deliveries reported by respondents. Using only data from each participant's last delivery, bivariate and multivariate logistic regression were used to describe associations between delivery location and a variety of covariates. Models were estimated with robust standard errors to account for clustering at the village level.

\section{Results}

A total of 959 women meeting inclusion criteria were interviewed, of which 895 were retained in the final database (see Figure 2). The ages of the respondents ranged from 18-49 with a mean age of 29.4 years (SD 6.3). Over half $(54.4 \%)$ of the respondents were married and an additional $31.2 \%$ were living with a man. Nearly $20 \%$ had never attended school, while the mean number of years of schooling among those who attended was 5.1 (SD 2.3). The primary occupation of the sampled women was subsistence agriculture, accounting for $90.1 \%$ of respondents. More than $86 \%$ of respondents were subscribers of a national community-funded health insurance program known as Mutuelle de Santé, while $10.9 \%$ did not have any form of health insurance. The majority of respondents (57.4\%) had given birth between 2-5 times, with a mean parity of 3.5 (SD 2.3) (see Table 1).

\section{Utilization of antenatal care}

Almost 99\% of respondents reported that they received some ANC during their last pregnancy. Over 95\% 


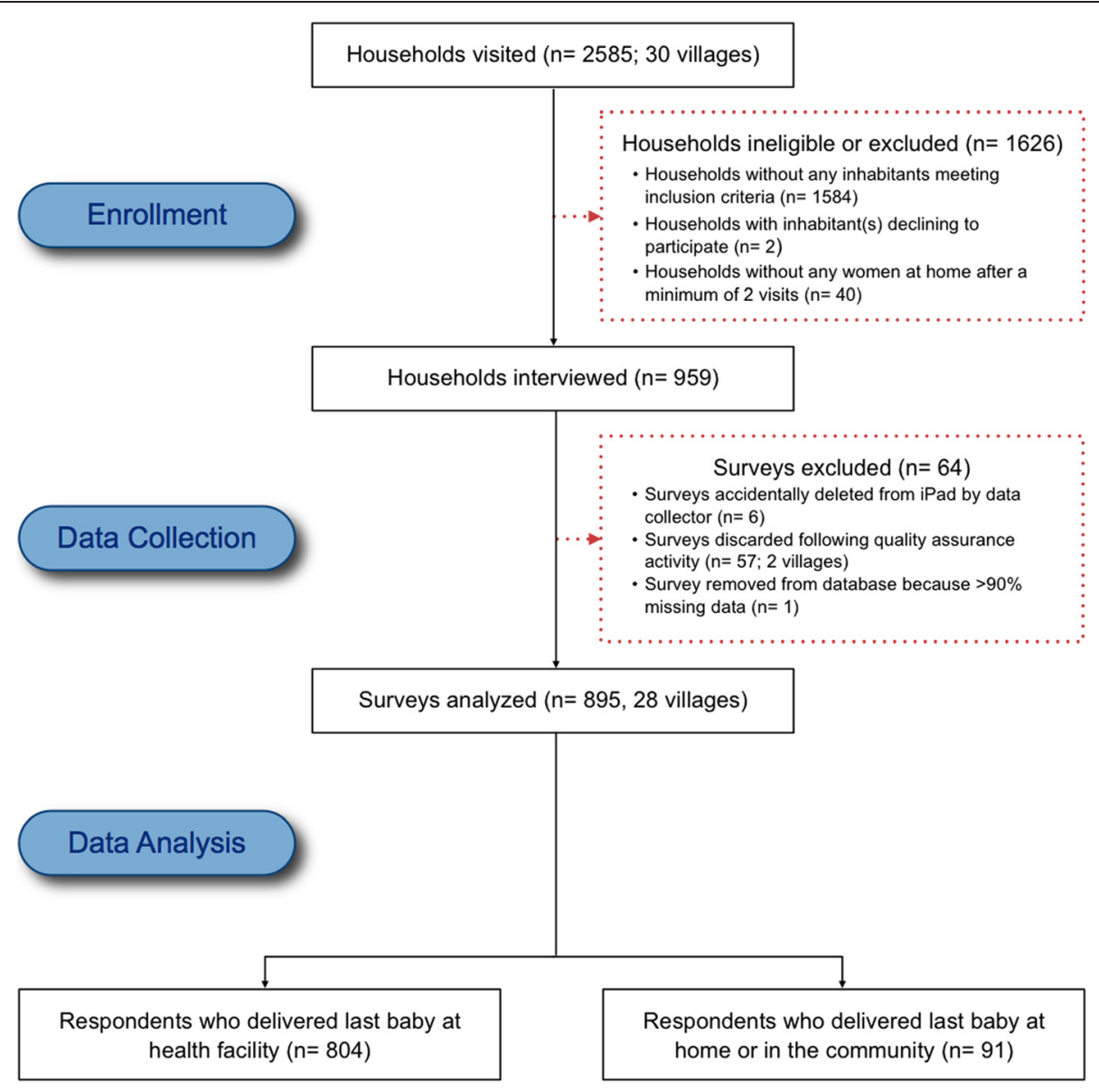

Figure 2 Sampling process.

attended at least two visits and $80.0 \%$ attended at least three visits, but only $31.7 \%$ attended four or more visits as recommended by the Rwandan Ministry of Health. The mean timing of the first ANC visit was at 4.1 months of pregnancy (SD 1.4), with just $40.8 \%$ of women attending their first ANC visit during the first trimester. Of women who attended at least one ANC visit, 86.6\% were accompanied by their husband or partner on one or more occasion. Further, of the respondents who attended ANC, 94.4\% reported that they were advised by a doctor, nurse, or TBA to deliver at a health facility. Forty-three percent of respondents stated that they were visited by a community health worker (CHW) during their pregnancy and $95.9 \%$ of these reported that they were advised by a CHW to deliver at a health facility.

\section{Utilization of delivery care}

During their most recent delivery, $89.8 \%$ of respondents reported delivering in a health facility. Of these, $80.2 \%$ delivered in a health center, $16.8 \%$ delivered at a district hospital, and 3.0\% delivered in a hospital in Kigali. Overall, $88.7 \%$ of women reported that a doctor and/or nurse attended their delivery. Among women who delivered in a health facility, 98.5\% benefitted from skilled attendance, compared to only $2.2 \%$ of women who delivered in the community. According to respondent recall, $89.1 \%$ of all deliveries were vaginal, $7.7 \%$ were Cesarean sections, and $3.2 \%$ were operative (vacuum or forceps).

Among respondents who delivered at a health facility, it took a mean of 52.7 minutes (SD 36.1) to reach the delivery location and the mean cost of transportation was 0.97 USD (SD 2.6). The median distance along roads from sampled villages to their designated health centers was $5.8 \mathrm{~km}(\mathrm{SD} 3.9, \min =0.9 \mathrm{~km}, \max =13.7 \mathrm{~km})$, while the median distance to Nyamata District Hospital was $24.8 \mathrm{~km}($ SD 10.4, $\min =1.3 \mathrm{~km}, \max =13.7 \mathrm{~km})$.

Figure 3 plots the location of all deliveries since 1990 over time. The data used to generate this figure was derived from a series of questions that asked respondents to list the year and delivery location for every pregnancy that progressed past 28 weeks, as described in the methods section. These data show an increase in health facility delivery rates in the sampled population over time, with a notable surge between 2006-2007 (from 
Table 1 General characteristics of 895 sampled women from 28 villages in Bugesera District, Rwanda

\begin{tabular}{|c|c|c|}
\hline & $\mathrm{N}$ & $\%$ \\
\hline \multicolumn{3}{|l|}{ Age } \\
\hline $18-24$ & 209 & $23.4 \%$ \\
\hline $18-24$ & 209 & $23.4 \%$ \\
\hline $25-33$ & 468 & $52.3 \%$ \\
\hline $34-49$ & 217 & $24.2 \%$ \\
\hline No response & 1 & $0.1 \%$ \\
\hline \multicolumn{3}{|l|}{ Marital Status } \\
\hline Married & 487 & $54.4 \%$ \\
\hline Living together & 279 & $31.2 \%$ \\
\hline Single (never married) & 73 & $8.2 \%$ \\
\hline Separated/divorced & 44 & $4.9 \%$ \\
\hline Widowed & 12 & $1.3 \%$ \\
\hline \multicolumn{3}{|l|}{ Education } \\
\hline No education & 178 & $19.9 \%$ \\
\hline Primary & 636 & $71.1 \%$ \\
\hline Secondary or higher & 81 & $9.1 \%$ \\
\hline \multicolumn{3}{|l|}{ Religion } \\
\hline Protestant & 374 & $41.8 \%$ \\
\hline Catholic & 310 & $34.7 \%$ \\
\hline Adventist & 204 & $22.8 \%$ \\
\hline Muslim & 6 & $0.7 \%$ \\
\hline No response & 1 & $0.1 \%$ \\
\hline \multicolumn{3}{|l|}{ Profession } \\
\hline Agriculture & 806 & $90.1 \%$ \\
\hline Self-employed/small business owner & 38 & $4.2 \%$ \\
\hline No work outside the home & 24 & $2.7 \%$ \\
\hline Unskilled employee & 22 & $2.5 \%$ \\
\hline Student & 5 & $0.6 \%$ \\
\hline \multicolumn{3}{|l|}{ Insurance } \\
\hline Mutuelle de Santé & 772 & $86.3 \%$ \\
\hline State Insurance (RAMA) & 14 & $1.6 \%$ \\
\hline Military Insurance (MMI) & 9 & $1.0 \%$ \\
\hline Private & 2 & $0.2 \%$ \\
\hline None & 98 & $10.9 \%$ \\
\hline \multicolumn{3}{|l|}{ Parity } \\
\hline 1 & 208 & $23.2 \%$ \\
\hline $2-5$ & 514 & $57.4 \%$ \\
\hline $6-13$ & 173 & $19.3 \%$ \\
\hline
\end{tabular}

$57.7 \%$ to $70.1 \%$ ), and another between 2008-2009 (from $79.7 \%$ to $90.4 \%)$.

\section{Determinants of utilization of delivery care}

The results of both the bivariate and multivariate logistic regressions are provided in Table 2 . In the bivariate analysis, health facility delivery was more common among younger women $(\mathrm{OR}=0.908[0.874-0.943]$ per year of age) and decreased with increasing parity ( $O R=0.795$ [0.738 - 0.856] for each additional birth). Women who had more schooling were more likely to deliver in a health facility $(\mathrm{OR}=1.136$ [1.042 - 1.239] per year of schooling). The education levels of the respondents' mothers, however, were not significant.

Participation in the management of household finances $(\mathrm{OR}=1.690[1.063-2.687])$ was predictive of health facility delivery, as was possessing health insurance $(\mathrm{OR}=5.683$ [3.186 - 10.14] $)$. Greater distance between the respondent's village and her designated health center was negatively associated with facility delivery $(\mathrm{OR}=0.888$ [0.839 - 0.941] per additional kilometer $)$, while the timing of labor commencement (day versus night) was not predictive of delivery location. A history of an offspring death was associated with decreased health facility delivery $(\mathrm{OR}=0.468[0.293-0.748])$. A history of prenatal, intrapartum, or postpartum complications, on the other hand, did not predict increased facility delivery.

Utilization of non-obstetric healthcare services $(\mathrm{OR}=$ 1.738 [1.091 - 2.768]) and delivering a penultimate baby at a health facility $(\mathrm{OR}=3.660$ [2.394 - 5.596]) were associated with higher rates of facility delivery, as were an increasing number of ANC visits (OR = 1.899 [1.473 - 2.447]) and attending an ANC visit with one's partner ( $\mathrm{OR}=1.949$ [1.235 - 3.075]). The number of visits by a CHW was not significant, nor was being advised by a healthcare provider to deliver at a health facility. Lastly, more recent delivery year (2008 to 2011) was associated with increased facility delivery $(\mathrm{OR}=1.578$ [1.254 - 1.986] per year).

In a multivariate logistic regression analysis, delivering a penultimate baby at a health facility $(\mathrm{OR}=4.681[3.204$ 6.839]), possessing health insurance ( $\mathrm{OR}=3.812$ [1.795 8.097]), participating in the management of household finances $(\mathrm{OR}=1.897$ [1.046 - 3.439]), attending a greater number of ANC visits (OR = 1.567 [1.163 - 2.112]), delivering more recently $(\mathrm{OR}=1.438$ [1.120 - 1.847] per year), and living in a village located closer to a health center $(\mathrm{OR}=$ 0.909 [0.846 - 0.976] per kilometer) were independently associated with facility delivery. Age and parity were jointly significant (not shown); however, due to their high correlation (rho $=0.470$ ) it was not possible to disentangle their independent effects in the multivariate model. The HosmerLemeshow goodness of fit test suggests no problems concerning the fit of our multivariate model $(\mathrm{p}=0.571)$ [25].

\section{Discussion}

Our study had two major findings. First, there has been a remarkable increase in the rate of health facility delivery in Bugesera District over time, with a particularly sharp increase over the past five years. Since 2009, over $90 \%$ of sampled women in Bugesera District delivered in health facilities; in contrast, only $42.9 \%$ of all subSaharan African women deliver in health facilities [8]. 


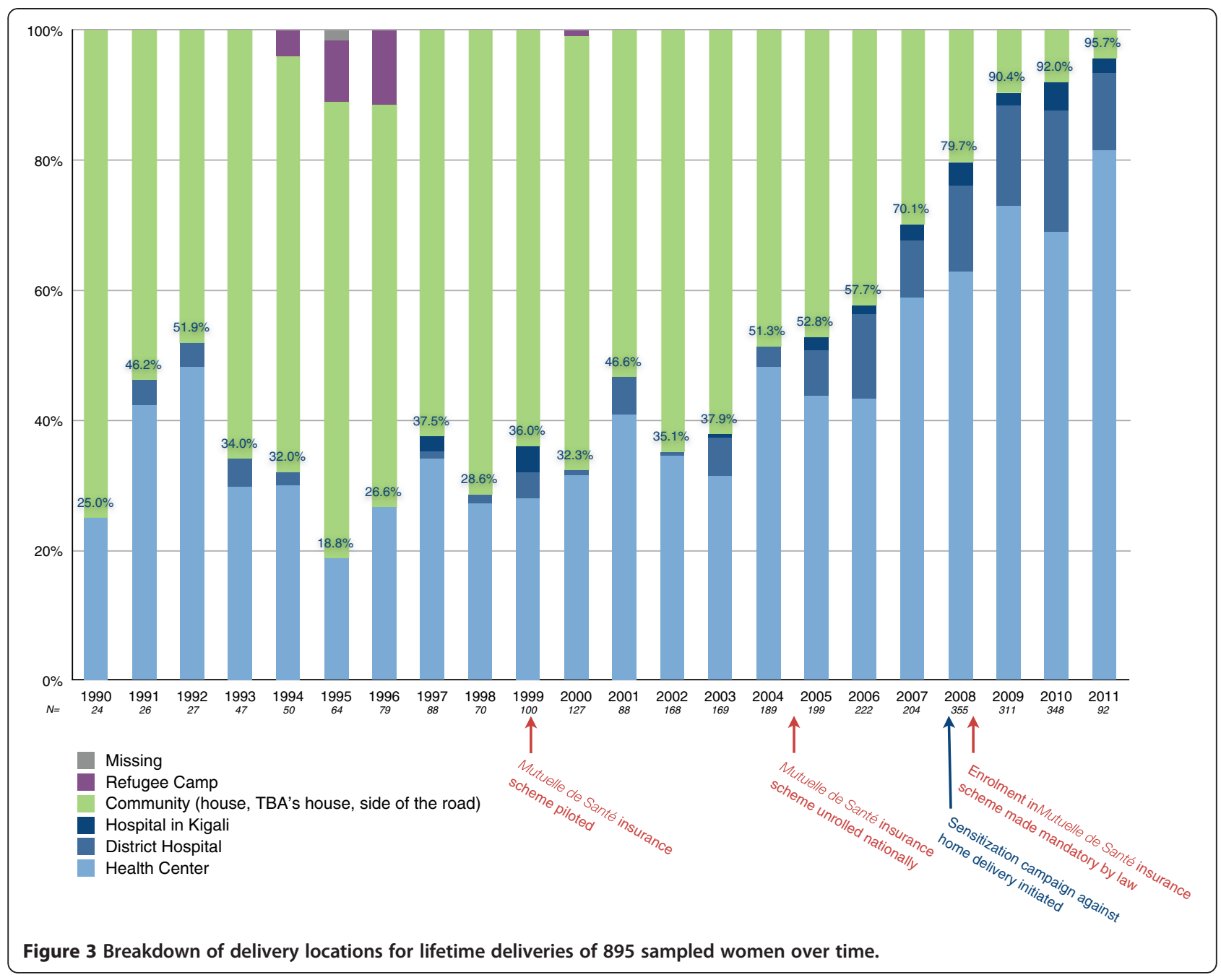

Second, multivariate logistic regression analysis suggests that delivering a penultimate baby at a health facility, possessing health insurance, having some control over household finances, attending more ANC visits, delivering more recently, and living closer to health centers are significantly associated with facility delivery.

The Government of Rwanda has set a progressive agenda towards improving its health indicators since the 1994 genocide, which left approximately one million people dead and the country's health infrastructure destroyed. Given the multitude of initiatives that have been introduced over the past 10-15 years, it is difficult to ascertain which structural intervention contributed most significantly to the improved uptake of skilled delivery care shown in our study. In reality, a number of interventions likely played a role, including the commitment of a dedicated political leadership to improved donor aid coordination; the refurbishment of most health facilities and many roads in the country; the implementation of a nation-wide performance-based payment initiative for healthcare providers; the national rollout of a community-financed health insurance program known as Mutuelle de Santé; the steady rise in overall health insurance subscription rates, from $68 \%$ household coverage in the 2007-8 Interim DHS to $78 \%$ household coverage in the 2010 DHS; and the inauguration of an aggressive sensitization campaign linked to performance contracts at the district level (imihigo) that aims to educate women on the dangers of delivering at home while strongly encouraging health facility delivery [9,10,20,26-28]. Disentangling the potential effects of each of these reforms in Rwanda's health sector is impossible. It is noteworthy, however that at least one detailed analysis of Ghana's National Health Insurance Scheme concluded that its implementation was not associated with increased use of maternal health services. Rather, the poor quality of facilities, cultural preferences to deliver at home, and lack of transportation were considered significant barriers [29].

While it is not clear from our data whether the observed increase in facility-based delivery in Bugesera District 
Table 2 Bivariate and multivariate logistic regression analysis correlates of health facility delivery for last deliveries among 895 women in Bugesera District, Rwanda

\begin{tabular}{|c|c|c|}
\hline & Bivariate & Multivariate \\
\hline & $(\mathrm{N}=891-895)^{5}$ & $(\mathrm{~N}=882)^{5}$ \\
\hline $\begin{array}{l}\text { Age }^{\ddagger} \\
(18-49 \text { years })\end{array}$ & $\begin{array}{l}0.908^{* * *} \\
{[0.874-0.943]}\end{array}$ & $\begin{array}{l}0.941 \\
{[0.872-1.015]}\end{array}$ \\
\hline $\begin{array}{l}\text { Married } \\
\quad \text { (unmarried vs. married) }\end{array}$ & $\begin{array}{l}1.188 \\
{[0.662-2.135]}\end{array}$ & $\begin{array}{l}0.783 \\
{[0.430-1.424]}\end{array}$ \\
\hline $\begin{array}{l}\text { Respondent's education (years of education) }{ }^{\ddagger} \\
(0-13)\end{array}$ & $\begin{array}{l}1.136^{* *} \\
{[1.042-1.239]}\end{array}$ & $\begin{array}{l}1.052 \\
{[0.975-1.135]}\end{array}$ \\
\hline $\begin{array}{l}\text { Mother's education } \\
\text { (no education vs. any education) }\end{array}$ & $\begin{array}{l}1.319 \\
{[0.774-2.249]}\end{array}$ & $\begin{array}{l}0.909 \\
{[0.524-1.580]}\end{array}$ \\
\hline $\begin{array}{l}\text { Financial control } \\
\text { (no control over family finances vs. some control) }\end{array}$ & $\begin{array}{l}1.690^{*} \\
{[1.063-2.687]}\end{array}$ & $\begin{array}{l}1.897^{*} \\
{[1.046-3.439]}\end{array}$ \\
\hline $\begin{array}{l}\text { Health insurance } \\
\text { (no health insurance vs. health insurance) }\end{array}$ & $\begin{array}{l}5.683^{* * *} \\
{[3.186-10.14]}\end{array}$ & $\begin{array}{l}3.812^{* * *} \\
{[1.795-8.097]}\end{array}$ \\
\hline $\begin{array}{l}\text { Parity }^{\ddagger} \\
(1-13)\end{array}$ & $\begin{array}{l}0.795^{* * *} \\
{[0.738-0.856]}\end{array}$ & $\begin{array}{l}0.873 \\
{[0.726-1.049]}\end{array}$ \\
\hline $\begin{array}{l}\text { Next-to-last delivery at facility } \\
\text { (no vs. yes) }\end{array}$ & $\begin{array}{l}3.660^{* * *} \\
{[2.394-5.596]}\end{array}$ & $\begin{array}{l}4.681^{* * *} \\
{[3.204-6.839]}\end{array}$ \\
\hline $\begin{array}{l}\text { Any offspring death } \\
\text { (no vs. yes) }\end{array}$ & $\begin{array}{l}0.468^{* *} \\
{[0.293-0.748]}\end{array}$ & $\begin{array}{l}0.84 \\
{[0.406-1.741]}\end{array}$ \\
\hline $\begin{array}{l}\text { Number of past intra/postpartum complications }{ }^{\ddagger} \\
(0-4)\end{array}$ & $\begin{array}{l}1.273 \\
{[0.808-2.006]}\end{array}$ & $\begin{array}{l}1 \\
{[0.582-1.719]}\end{array}$ \\
\hline $\begin{array}{l}\text { Any prenatal complications } \\
\text { (no vs. yes) }\end{array}$ & $\begin{array}{l}1.309 \\
{[0.653-2.625]}\end{array}$ & $\begin{array}{l}1.122 \\
{[0.527-2.386]}\end{array}$ \\
\hline $\begin{array}{l}\text { Number of antenatal clinic visits }{ }^{\ddagger} \\
(0-9)\end{array}$ & $\begin{array}{l}1.899^{* * *} \\
{[1.473-2.447]}\end{array}$ & $\begin{array}{l}1.567^{* *} \\
{[1.163-2.112]}\end{array}$ \\
\hline $\begin{array}{l}\text { Any antenatal clinic visits with partner } \\
\text { (no vs. yes) }\end{array}$ & $\begin{array}{l}1.949 * * \\
{[1.235-3.075]}\end{array}$ & $\begin{array}{l}1.246 \\
{[0.726-2.141]}\end{array}$ \\
\hline $\begin{array}{l}\text { Community health worker visits }^{\ddagger} \\
(0-20)\end{array}$ & $\begin{array}{l}1.069 \\
{[0.925-1.236]}\end{array}$ & $\begin{array}{l}1.173 \\
{[0.954-1.442]}\end{array}$ \\
\hline $\begin{array}{l}\text { Use of non-obstetric services at health facility } \\
\text { (no vs. yes) }\end{array}$ & $\begin{array}{l}1.738^{*} \\
{[1.091-2.768]}\end{array}$ & $\begin{array}{l}1.171 \\
{[0.704-1.950]}\end{array}$ \\
\hline $\begin{array}{l}\text { Advised by healthcare provider } \\
\text { (no vs. yes) }\end{array}$ & $\begin{array}{l}1.785 \\
{[0.787-4.051]}\end{array}$ & $\begin{array}{l}1.619 \\
{[0.534-4.908]}\end{array}$ \\
\hline $\begin{array}{l}\text { Timing of labor } \\
\text { (night vs. day) }\end{array}$ & $\begin{array}{l}1.089 \\
{[0.665-1.783]}\end{array}$ & $\begin{array}{l}1.076 \\
{[0.608-1.907]}\end{array}$ \\
\hline $\begin{array}{l}\text { Distance (kilometers) }{ }^{\ddagger} \\
\quad(0-14)\end{array}$ & $\begin{array}{l}0.888^{* * *} \\
{[0.839-0.941]}\end{array}$ & $\begin{array}{l}0.909^{* *} \\
{[0.846-0.976]}\end{array}$ \\
\hline $\begin{array}{l}\text { Time }(\text { year })^{\ddagger} \\
(2008-2011)\end{array}$ & $\begin{array}{l}1.578^{* * *} \\
{[1.254-1.986]}\end{array}$ & $\begin{array}{l}1.438^{* *} \\
{[1.120-1.847]}\end{array}$ \\
\hline
\end{tabular}

Odds ratios and $95 \%$ confidence intervals; standard errors adjusted for clustering at the village level.

${ }^{*}$ denotes $\mathrm{p}<0.05,{ }^{* *}$ denotes $\mathrm{p}<0.01{ }^{* * *}$ denotes $\mathrm{p}<0.001 \neq$ denotes a continous variable.

resulted in decreased maternal mortality, our results are in and of themselves encouraging. Given the impressive percentage of women presenting for delivery at health facilities, a reasonable next step in addressing maternal mortality in Bugesera District would be to shift focus from promoting skilled attendance to improving the quality of ANC and delivery care at health facilities, primarily by upgrading the knowledge of health professionals so as to meet WHO standards for skilled attendants [4]. This is especially important given the demonstrated lack of competence among purportedly skilled attendants in Rwanda and other developing countries when judged against WHO standards [30-32].

There are several possible limitations to our study. First, as in all cross-sectional studies, we can infer association but not causation from our results. Second, social desirability bias could have artificially inflated the reported rates of health facility delivery; however, the study was confidential and data collectors were instructed to assure women that their responses could not be linked to them. Third, our sample did not include adolescents younger than 18 years old. Regression 
analysis indicates that younger women were more likely to deliver in health facilities, suggesting that inclusion of this group may have led to increased overall facility delivery rates. Finally, our study was limited to 28 villages in one district and thus the findings cannot be extrapolated to the country as a whole; on the other hand, trends in facility-based deliveries between 2006-2010 in our data were similar to trends observed in the most recent DHS [10]. While the health facility delivery rate for our sample during this time period $(80.2 \%)$ was higher than the country-wide rate $(68.9 \%)$ reported by the 2010 DHS, national data show similar trends, suggesting that our district-wide sample was not dissimilar to the latest DHS sample. For this reason, it is reasonable to assume that factors that correlate with delivery uptake in health facilities in Bugesera District would likely play a similar role in other districts in Rwanda. Moreover, even though it is not possible to generalize our results to the country as a whole, having district-level data is particularly important in Rwanda given the recent implementation of a comprehensive national decentralization strategy. Among other changes, decentralization yielded 30 districts, which function as the unit of implementation for major central government policies and social programs; accordingly, having estimates of maternal health indicators at the district level will inform planning, budgeting, and monitoring processes.

\section{Conclusions}

The dramatic improvement in the health facility delivery rate in Bugesera District likely reflects a number of important structural interventions, including the rapid scale-up of the Mutuelle de Santé, to which a considerable majority of Rwandans now subscribe. If the trend in improved uptake of skilled delivery care in Bugesera holds true for the nation, Rwanda should make substantial progress towards achieving MDG 5. While further research is needed to determine how best to encourage facility-based delivery among those women who continue to deliver in the community, the results of our multivariate analysis lead us to suggest that sensitization campaigns target women who delivered their last baby at home and/or attended few ANC visits. Further, we argue that renewing efforts to achieve universal health insurance and to promote women's empowerment, in addition to increasing access to transportation services, could also help to promote facility deliveries in the district.

\section{Abbreviations}

ANC: Antenatal Care; CHW: Community Health Worker; DHS: Demographic Health Survey; MDG: Millennium Development Goal.

\section{Competing interests}

The authors declare that they have no disclosures or competing interests.

\section{Authors' contributions}

SJ, NT, JW, JO, and SR designed the study. SJ, FN, and AW executed the study. SJ, JO, NT, and AW completed the analysis. SJ authored the manuscript and received additional review and input from NT, JW, JO, AW, and FS. All authors read and approved the final manuscript.

\section{Acknowledgements}

The authors wish to thank the staff at the Rwandan Ministry of Health and the National Institute of Statistics for their assistance and guidance. We are particularly grateful to Mr. Francis Karambizi of the Bugesera District Health Office for his invaluable help, as well as our six surveyors and driver for their dedication to collecting quality data. We would also like to recognize Dr. Edmond Ntaganda for his conscientious translations of the survey instrument and Mr. Wenfeng Gong for his expert assistance with ArcGIS. Finally, we would like to thank the women of Bugesera District for welcoming us into their homes and patiently answering our long list of questions.

\section{Funding}

The study was funded in part by the Bill and Melinda Gates Foundation and University of Michigan Landscaping Grant, with additional financial support from the Kaplan Foundation. SJ received financial support from the HubertYeargan Center for Global Health at Duke University Medical Center.

\section{Author details}

${ }^{1}$ Department of Surgery, Division of General Surgery, University of British Columbia, Vancouver, BC, Canada. ${ }^{2}$ Department of Clinical Research, Kigali University Teaching Hospital, Kigali, Rwanda. ${ }^{3}$ National University of Rwanda, Butare, Rwanda. ${ }^{4}$ Gillings School of Global Public Health, University of North Carolina at Chapel Hill, Chapel Hill, NC, USA. ${ }^{5}$ Ministry of Health, Republic of Rwanda, Kigali, Rwanda. ${ }^{6}$ Department of Obstetrics and Gynecology, University of North Carolina at Chapel Hill, Chapel Hill, NC, USA. ${ }^{7}$ Duke Global Health Institute, Duke University, Durham, NC, USA.

Received: 28 April 2012 Accepted: 29 November 2012

Published: 5 December 2012

\section{References}

1. Hogan MC, et al: Maternal mortality for 181 countries, 1980-2008: a systematic analysis of progress towards millennium development goal 5 . Lancet 2010, 375(9726):1609-1623.

2. Bhutta ZA, et al: Countdown to 2015 decade report (2000-10): taking stock of maternal, newborn, and child survival. Lancet 2010, 375(9730):2032-2044.

3. WHO, World Bank, UNICEF, United Nations Population Fund: Trends in maternal mortality: 1990 to 2008. Geneva: 2010. http://whqlibdoc.who.int/ publications/2010/9789241500265_eng.pdf.

4. WHO: Making pregnancy safer: the critical role of the skilled attendant: a joint statement. Geneva: WHO, ICM and FIGO; 2004.

5. Adegoke AA, van den Broek N: Skilled birth attendance-lessons learnt. BJOG 2009, 116(Suppl 1):33-40.

6. Stanton $C$, et al: Skilled care at birth in the developing world: progress to date and strategies for expanding coverage. J Biosoc Sci 2007, 39(1):109-120.

7. Sibley LM, et al: Traditional birth attendant training for improving health behaviours and pregnancy outcomes. Cochrane Database Syst Rev 2007, 3:CD005460.

8. Montagu $D$, et al: Where do poor women in developing countries give birth? A multi-country analysis of demographic and health survey data. PLoS One 2011, 6(2):e1715.

9. Rwandan Ministry of Health, Rwandan Ministry of Health, National Institute of Statistics of Rwanda, and ICF International: Rwanda interim demographic and health survey 2007-08. Calverton, Maryland, U.S.A: MOH, NISR, and ICF Macro; 2009.

10. Rwandan Ministry of Health, National Institute of Statistics of Rwanda, and ICF International: Rwanda demographic and health survey 2010. Maryland, U.S.A: MOH, NISR, and ICF Macro; 2012.

11. Bazant ES, Koenig MA: Women's satisfaction with delivery care in Nairobi's informal settlements. Int J Qual Health Care 2009, 21(2):79-86.

12. Cotter K, Hawken M, Temmerman M: Low use of skilled attendants' delivery services in rural Kenya. J Health Popul Nutr 2006, 24(4):467-471. 
13. Essendi H, Mills S: Barriers to formal emergency obstetric care Services' utilization. J Urban Health 2010, 88(S2):356-369. doi:10.1007/s11524-0109481-1.

14. Kruk ME, et al: Women's preferences for obstetric care in rural Ethiopia: a population-based discrete choice experiment in a region with low rates of facility delivery. J Epidemiol Community Health 2010, 64(11):984-8.

15. Kruk ME, et al: Women's preferences for place of delivery in rural Tanzania: a population-based discrete choice experiment. Am J Public Health 2009, 99(9):1666-72.

16. Kyomuhendo GB: Low use of rural maternity services in Uganda: impact of women's status, traditional beliefs and limited resources. Reprod Health Matters 2003, 11(21):16-26.

17. Magoma M, et al: High ANC coverage and low skilled attendance in a rural Tanzanian district: a case for implementing a birth plan intervention. BMC Pregnancy Childbirth 2010, 10:13.

18. Mpembeni RN, et al: Use pattern of maternal health services and determinants of skilled care during delivery in Southern Tanzania: implications for achievement of MDG-5 targets. BMC Pregnancy Childbirth 2007, 7:29.

19. Rockers $P C$, et al: Source of antenatal care influences facility delivery in rural Tanzania: a population-based study. Matern Child Health J 2009, 13(6):879-85.

20. Logie $D E$, Rowson M, Ndagije F: Innovations in Rwanda's health system: looking to the future. Lancet 2008, 372(9634):256-61.

21. République de Rwanda: Monographie du district de bugesera. Province de I'Est. 2006.

22. Bugesera District Office: Fiches de collecte des données exacte. Rwanda: Nyamata, Bugesera District; 2011. http://www.easternprovince.gov.rw/ documents/bugesera/monographie_bugesera.pdf.

23. Rwanda ministry of health maternal and child health data tables. http://moh gov.rw/english/wp-content/uploads/2012/05/MCH-Data-in-Tables.xls.

24. Bennett $\mathrm{S}$, et al: A simplified general method for cluster-sample surveys of health in developing countries. World Health Stat Q 1991, 44(3):98-106.

25. Hosmer DW, Lemeshow S: Applied logistic regression. 2nd ed. Wiley series in probability and statistics texts and references section. New York: Wiley; 2000: xii, 373.

26. Basinga $P$, et al: Effect on maternal and child health services in Rwanda of payment to primary health-care providers for performance: an impact evaluation. Lancet 2011, 377(9775):1421-8.

27. Twahirwa A: Sharing the burden of sickness: mutual health insurance in Rwanda. Bull World Health Organ 2008, 86(11):823-4.

28. Hong R, Ayad M, Ngabo F: Being insured improves safe delivery practices in Rwanda. J Community Health 2011, 36(5):779-784.

29. Chankova S, Atim Y, Hatt C, Griffin C, Shaw R: L Ghana's national health insurance scheme. In Health insurance in Low- and middle-income countries. Edited by Escobar M. Washington, DC: Brookings Institute Press; 2010:588-88.

30. Harvey SA, et al: Skilled birth attendant competence: an initial assessment in four countries, and implications for the safe motherhood movement. Int J Gynaecol Obstet 2004, 87(2):203-210.

31. Harvey SA, et al: Are skilled birth attendants really skilled? A measurement method, some disturbing results and a potential way forward. Bull World Health Organ 2007, 85(10):783-790.

32. Puri $\mathrm{R}$, et al: Knowledge, attitudes and practices in safe motherhood care among obstetric providers in Bugesera. Rwanda: Int J Gynaecol Obstet, 2012, 116(2):124-127.

doi:10.1186/1471-2458-12-1049

Cite this article as: Joharifard et al.: Prevalence and predictors of giving birth in health facilities in Bugesera District, Rwanda. BMC Public Health 2012 12:1049.

\section{Submit your next manuscript to BioMed Central and take full advantage of:}

- Convenient online submission

- Thorough peer review

- No space constraints or color figure charges

- Immediate publication on acceptance

- Inclusion in PubMed, CAS, Scopus and Google Scholar

- Research which is freely available for redistribution

Submit your manuscript at www.biomedcentral.com/submit
Ciomed Central 